\title{
Does age influence normal gastro-oesophageal reflux?
}

\author{
R A J SPENCE, B J COLlins, T G PARKS, AND A H G LOVE \\ From the Departments of Medicine and Surgery, The Queen's University of Belfast, Belfast, Northern Ireland
}

SUMMARY Prolonged oesophageal pH monitoring is being used increasingly to detect abnormal gastro-oesophageal reflux. To assess the influence of age on normal reflux patterns, a group of 13 young asymptomatic subjects (mean age 22 years) was compared with a group of 14 middle aged asymptomatic subjects (mean age 49 years). An ambulatory system using a radiotelemetry capsule and a portable receiving system was used, oesophageal $\mathrm{pH}$ being recorded for at least 16 hours during an overnight hospital stay under standardised conditions. There was no significant difference in the duration or frequency of reflux episodes as defined by $\mathrm{pH}<5,<4,<3$, or as a fall in $\mathrm{pH}$ of more than two units. It is concluded that it is an acceptable practice to use young volunteers to establish normal values in reflux studies of young and middle aged patients.

Prolonged $\mathrm{pH}$ monitoring of the lower oesophagus is regarded as the most sensitive indicator of abnormal gastro-oesophageal reflux when compared with any other single investigation. ${ }^{12}$ Increasingly, the technique is being used to distinguish 'refluxers' from 'non-refluxers' ${ }^{3} 4$ to assess the effect of gastric surgery on the function of the lower oesophageal sphincter, ${ }^{5}$ to assess patients with non-cardiac chest pain $^{6}$ and to evaluate anti-reflux surgical procedures. ${ }^{7}$ Published control data with this investigation, however, are limited and no studies have considered the influence of age on normal reflux patterns. We have carried out oesophageal $\mathrm{pH}$ studies under standardised conditions in a group of middle aged asymptomatic subjects and compared their reflux data with that of a group of young control subjects.

\section{Methods}

\section{SUBJECTS}

The middle aged group was composed of 14 subjects (six women) of mean age 49 years, (range 39-61 years). The young group was composed of 13 subjects (four women) of mean age 22 years (range 19-30 years). All subjects from both groups denied any reflux symptoms, none had suffered from any gastrointestinal tract disease and none consumed excessive alcohol. None of the subjects, either young or middle aged, was taking any drugs. Two of

Address for correspondence: R A J Spence, MD FRCS, Department of Surgery, The Queen's University of Belfast, Institute of Clinical Science, Grosvenor Road, Belfast BT12 6BJ.

Received for publication 10 September 1984 the young control group smoked cigarettes, while six of the middle aged control group smoked cigarettes.

Prolonged ambulatory oesophageal $\mathrm{pH}$ monitoring was carried out with a $\mathrm{pH}$ sensitive radiotelemetry capsule (Model 7006, Rigel Research) and a portable receiving system which consisted of a battery operated FM receiver and aerial switching unit. The signal was recorded on a Medilog four channel recorder (Oxford Medical Systems). This method has been described previously. ${ }^{8}$

The oesophagogastric junction was located using a station pull-through technique of oesophageal manometry, and the radiotelemetry capsule was tethered in the oesophagus, $5 \mathrm{~cm}$ above the lower sphincter using fine polyvinyl tubing. All studies were conducted during an overnight hospital stay. Subjects were fully mobile, but activity was standardised to allow comparison between the groups. Food and drink of $\mathrm{pH}<5$ were excluded from the diet.

The aerial was worn across the chest throughout the period of $\mathrm{pH}$ monitoring, but at night the belt containing the receiver and recorder was placed at the bedside. The 24-hour tape was played back on a Devices MX4 unit with an Oxford PB2 replay module using three PM3 demodulations.

Allowing for periods of signal loss, shown on channel 2 of the recording, the corrected time of recording of $\mathrm{pH}$ for both erect and supine periods was calculated. Both the duration (minutes) and number of reflux episodes, defined as a fall in $\mathrm{pH}$ for $<5,<4$, or $<3$, were recorded. Similarly, the duration and frequency of reflux episodes, defined as a fall of $2 \mathrm{pH}$ units, were noted. All results were 
expressed per recorded hour and reflux data for daytime (erect) and night (supine) were analysed separately.

\section{Results}

Corrected median time of $\mathrm{pH}$ recording, while erect, in the middle aged group was 8.8 hours (range $8 \cdot 3-12 \cdot 2$ hours), while median time of supine recording was $8 \cdot 25$ hours (range $6 \cdot 4-9 \cdot 6$ hours). For the young group corrected median time of recording, while erect, was 8.75 hours (range $6.5-12$ hours) and median time of supine recording was 7.5 hours (range 6.5-10 hours). Mean lower oesophageal sphincter pressure in the young control group was $19.1 \mathrm{mmHg}$, range $8.8-15.7 \mathrm{mmHg}$. Mean sphincter pressure in the middle age group was $18.2 \mathrm{mmHg}$; range $10 \cdot 0-29.9 \mathrm{mmHg}$. There was no significant difference in mean sphincter pressure between the two groups.

The reflux data for the young and middle aged volunteer were compared using the Mann-Whitney $\mathrm{U}$ test. A separate comparison was made of the erect and supine data. The duration and frequency of reflux episodes while erect or supine are detailed in the Table. There was no significant difference between the young and middle aged groups in either frequency or duration of erect or supine reflux episodes.

\section{Discussion}

With the increasing use of prolonged oesophageal $\mathrm{pH}$ monitoring as a diagnostic test, ${ }^{8-11}$ it is im- portant to establish normal control values. Scoring systems have been devised for nocturnal reflux episodes and for reflux occurring when erect. ${ }^{3} 12$ Most studies of prolonged $\mathrm{pH}$ monitoring have used young control subjects, however, often medical students, whose cooperation is more readily obtained than that of a group of middle aged asymptomatic subjects. Such data from young subjects have frequently been used to define abnormal reflux in middle aged patients with oesophageal or gastric disease. The validity of so doing has not been tested previously.

The present study confirms that normal asymptomatic subjects, whether young or middle aged, experience intermittent gastro-oesophageal reflux. Reflux episodes occur more frequently during the daytime than at night. It is possible that the main underlying mechanism is transient lower oesophageal sphincter relaxation, ${ }^{13}$ as none of our subjects had an abnormally low sphincter pressure or sphincter length.

We have detected no significant difference between young and middle aged asymptomatic volunteers in the pattern of reflux, either while erect or supine. Thus, it is reasonable that young asymptomatic volunteers be used to establish normal values for reflux and that their reflux data be compared with young and middle aged patients under investigation.

Janssen Pharmaceuticals Ltd provided financial support for this study. We thank Sister E Crawford who assisted with manometric studies.

Table Prolonged pH monitoring in young and middle aged asymptomatic subjects. Median (range).

\begin{tabular}{|c|c|c|c|c|}
\hline & \multicolumn{2}{|l|}{ Erect } & \multicolumn{2}{|l|}{ Supine } \\
\hline & $\begin{array}{l}\text { Young controls } \\
(n=13)\end{array}$ & $\begin{array}{l}\text { Middle aged } \\
\text { controls } \\
(n=14)\end{array}$ & $\begin{array}{l}\text { Young controls } \\
(n=13)\end{array}$ & $\begin{array}{l}\text { Middle aged } \\
\text { controls } \\
(n=14)\end{array}$ \\
\hline $\begin{array}{l}\text { Time } \mathrm{pH}<5 \\
(\mathrm{~min} / \mathrm{h})\end{array}$ & 1.4 & $2 \cdot 37$ & $0 \cdot 15$ & $0 \cdot 24$ \\
\hline Episodes/h (no) & 0.29 & $\begin{array}{l}(0.00-3 \cdot 39) \\
0 \cdot 36\end{array}$ & $\begin{array}{l}(0 \cdot 0-2 \cdot 1) \\
0 \cdot 1\end{array}$ & $\begin{array}{l}(0 \cdot 0-5 \cdot 104) \\
0 \cdot 115\end{array}$ \\
\hline$(\mathrm{pH}<5)$ & $(0.08-0 \cdot 58)$ & $(0 \cdot 08-0 \cdot 71)$ & $(0.0-0.97)$ & $(0.0-0.44)$ \\
\hline Time $\mathrm{pH}<4$ & 1.30 & 1.98 & 0.15 & $0 \cdot 19$ \\
\hline$(\min / \mathrm{h})$ & $(0 \cdot 31-3 \cdot 75)$ & $(0 \cdot 42-3 \cdot 21)$ & $(0 \cdot 0-0 \cdot 19)$ & $(0.0-4.43)$ \\
\hline Episodes/h (no) & 0.235 & 0.305 & $0 \cdot 10$ & $0 \cdot 115$ \\
\hline$(\mathrm{pH}<4)$ & $(0.08-0.58)$ & $(0.07-0 \cdot 71)$ & $(0.0-0.92)$ & $(0 \cdot 0-0 \cdot 26)$ \\
\hline Time $\mathrm{pH}<3$ & $0 \cdot 0$ & 0.39 & 0.0 & 0.0 \\
\hline$(\min / \mathrm{h})$ & $(0 \cdot 0-2 \cdot 5)$ & $(0 \cdot 0-1 \cdot 71)$ & $(0 \cdot 0-1 \cdot 75)$ & $(0.0-0.87)$ \\
\hline Episodes/h (no) & 0.0 & 0.22 & 0.0 & \\
\hline$(\mathrm{pH}<3)$ & $(0 \cdot 0-0 \cdot 40)$ & $(0.0-0.36)$ & $(0.0-0.61)$ & $(0 \cdot 0-0 \cdot 14)$ \\
\hline $\mathrm{pH}$ fall $>2$ units & $1 \cdot 30$ & $2 \cdot 27$ & 0.15 & 0.06 \\
\hline$(\mathrm{min} / \mathrm{h})$ & $(0 \cdot 0-4 \cdot 37)$ & $(0 \cdot 0-5 \cdot 13)$ & $(0 \cdot 0-2 \cdot 0)$ & $(0 \cdot 0-4.88)$ \\
\hline Episodes/h (no) & 0.22 & 0.34 & $0 \cdot 10$ & 0.06 \\
\hline ( $\mathrm{pH}$ fall $>2$ units) & $(0 \cdot 0-0 \cdot 76)$ & $(0.0-0.8)$ & $(0.0-0.92)$ & $(0 \cdot 0-0.40)$ \\
\hline
\end{tabular}




\section{References}

1 DeMeester TR, Johnson LF. The evaluation of objective measurements of gastroesophageal reflux and their contribution to patient management. Surg Clin North Am 1976; 56: 39-53.

2 Holloway RH, McCallum RW. New diagnostic techniques in esophageal disease. In: Cohen S, Soloway RD, eds. Diseases of the esophagus. London: Churchill Livingstone, 1982: 75-95.

3 Johnson LF, DeMeester TR. Twenty-four hour $\mathrm{pH}$ monitoring of the distal esophagus. Am J Gastroenterol 1974; 62: 325-32.

4 DeMeester TR, Wang C-I, Wernly JA et al. Technique, indications and clinical use of 24-hour esophageal pH monitoring. J Thorac Cardiovasc Surg 1980; 79: 656-67.

5 O'Sullivan GC, DeMeester TR, Smith RB et al. Twenty-four hour $\mathrm{pH}$ monitoring of esophageal function. Its use in evaluation of symptomatic patients after truncal vagotomy and gastric resection on drainage. Arch Surg 1981; 116: 581-90.

6 DeMeester TR, O'Sullivan GC, Bermudez G et al. Esophageal function in patients with angina-type chest pain and normal coronary angiograms. Ann Surg 1982;
196: 488-98.

7 DeMeester TR, Johnson LF. Evaluation of the Nissen anti-reflux procedure by esophageal manometry and twenty-four hour pH monitoring. Am J Surg 1975; 129: 94-100.

8 Branicki FJ, Evans DF, Ogilvie AL et al. Ambulatory monitoring of oesophageal $\mathrm{pH}$ in reflux oesophagitis using a portable radiotelemetry system. Gut 1982; 23: 992-98.

9 Bennett JR, Buckton G, Morton HD. Cimetidine in gastroesophageal reflux. Digestion 1983; 26: 166-72.

10 Jolley SG, Johnson DG, Herbst JJ, Pena A, Garnier R. An assessment of gastroesophageal reflux in children by extended $\mathrm{pH}$ monitoring of the distal esophagus. Surgery 1978; 84: 16-24.

11 Atkinson M, Van Gelden A. Esophageal intraluminal $\mathrm{pH}$ recording in the assessment of gastroesophageal reflux and its consequences. Am J Dig Dis 1977; 22: 365-70.

12 DeMeester TR, Johnson LF, Joseph GT et al. Patterns of gastroesophageal reflux in health and disease. Ann Surg 1976; 184: 459-70.

13 Dodds WJ, Hogan WJ, Helm JF, Dent J. Pathogenesis of reflux esophagitis. Gastroenterology 1981; 81: 37694. 